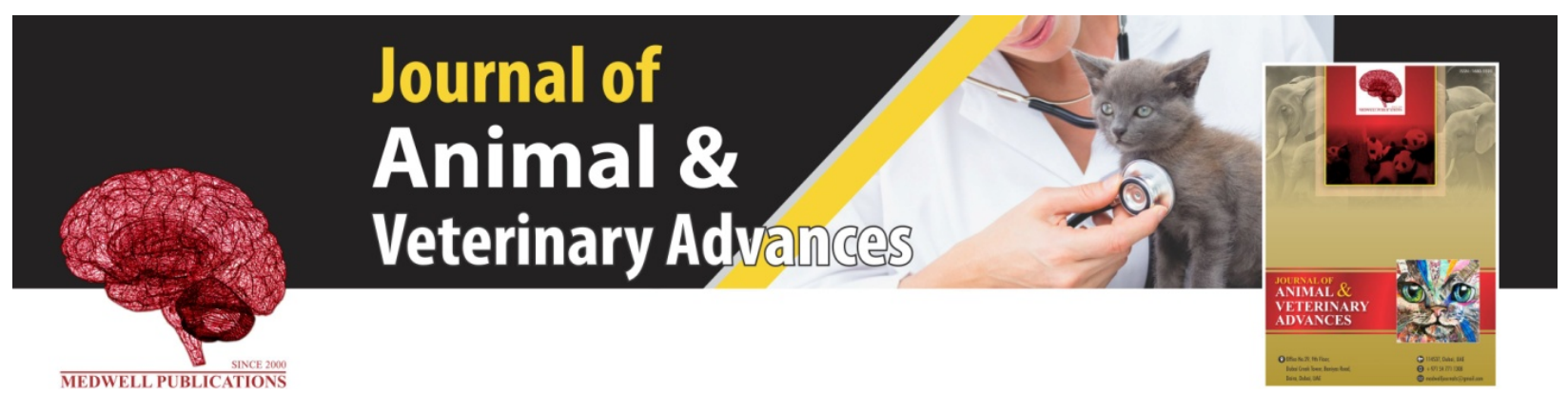

\title{
Dietary Supplementation with Omega-3 Poly Unsaturated Fatty Acids Improves the Fertility
} in Adult Male Rats

${ }^{1}$ Noura El SayedAbd El-Hameed, ${ }^{1}$ Adel Abd El-Tawab El Badry and ${ }^{2}$ WafaaElSayed Mohamed Dina Mousa

${ }^{1}$ Department of Physiology, Faculty of Veterinary Medicine, Zagazig University, Zagazig, Egypt

${ }^{2}$ Faculty of Girls, Ainshams University, Cairo, Egypt

Key words: Omega-3 PUNFs, semen parameters, testosterone, antioxidants, male fertility

Corresponding Author:

Noura El SayedAbd El-Hameed

Department of Physiology, Faculty of Veterinary Medicine, Zagazig University, Zagazig, Egypt

Page No.: 315-322

Volume: 18, Issue 11, 2019

ISSN: $1680-5593$

Journal of Animal and Veterinary Advances

Copy Right: Medwell Publications
Abstract: This study aimed to assess the role of omega-3 PUNFs on male fertility using albino rats in order to get benefit from its use. For this study, fiftsy mature male albino rats weighing 250-300 $\mathrm{g}$ and aged 4-6 months were allocated randomly into 2 equal groups; group A that kept as control $(\mathrm{n}=25)$ and group $\mathrm{B}(\mathrm{n}=25)$ where rats subjected to oral administration of omega-3 for 2 months in a dose of $375 \mathrm{mg} \mathrm{kg}^{-1}$ body weight daily. The semen was collected from both groups after 8 weeks for detecting the sperm motility, count and abnormalities. Sera were used for determination of testosterone level. In addition, testis homogenate was used for measuring catalase and malondialdehyde activity. The body weight and sex organs (testis, prostate gland and seminal vesicles) weights were recorded in both groups. Histological examination of testis was performed. The obtained results revealed that group B; omega-3 treated group showed a significant increase in sperm motility, count, testosterone and catalase concentrations with a significant decrease in the percentage of abnormal spermatozoa and malondialdehyde concentration as compared with group A; control. Nochange in both body and sex organs weights was observed in treated group. In addition, numerous sperms in the lumen of the seminiferous tubules with numerous active spermatocytes were observed in the testis of omega-3 treated group. It was concluded that omega-3 PUNFs had a positive and useful effects on the male fertility and could improve semen quality.

\section{INTRODUCTION}

Infertility is considered one of the important problems of human society where it is influenced by many environmental, behavioral, genotoxic and genetic factors causing impaired spermatogenesis at various stages and male infertility (Toshimori et al., 2004). Several chemical drugs were used to treat infertility but some had a side effect, so, the researchers are looking for using drugs with less adverse effects and toxicity (Austin, 1991). The 
changes in diet habits nowadays caused a decrease in the intake of antioxidants and micronutrients which is important for the maturation of spermatozoa and prevention of oxidative stress (Giahi et al., 2015). Seminal oxidative stress is a result of the imbalance between Reactive Oxygen Species (ROS) generation and scavenging activities. Furthermore, spermatozoa are especially, susceptible to ROS damage (Saleh and Agarwal, 2002). So, it was suggested to use antioxidant therapy to improve the semen quality and treat infertility problems in male (Esmaeili et al., 2015). Omega-3 PUFAs considered one of the important antioxidants that had a great safety profile, so, it could be used to improve the semen quality (Brinsko et al., 2005).

Omega-3 Poly Unsaturated Fatty Acids (PUFAs) considered essential fatty acids where they cannot be made by the human body and must be obtained from dietary sources that derived mostly from fish oil. They have a double bond $(\mathrm{C}=\mathrm{C})$ at the third carbon atom from the end of the carbon chain that are important for optimal health (Scorletti and Byrne, 2013).

The three types of omega-3 PUFAs involved in human physiology are $\alpha$-Linolenic Acid (ALA) which found in plant oils, Eicosapentaenoic Acid (EPA) and Docosahexaenoic Acid (DHA) that commonly found in marine oils. Marine algae and phytoplankton considered primary sources of omega-3 PUFAs (Rizos et al., 2012).

There are several experimental and epidemiological data indicating that the consumption of omega-3 FAs decreases the risk of various diseases. The benefit of the high omega-3 FAs intake is attributed to their ability to modulate cellular metabolic functions and gene expression (Seo et al., 2005). In addition, they have a significant anti-inflammatory effect via. different mechanisms including the eicosanoid metabolites, thromboxane, prostaglandins, leukotriene and prostacyclin as well as by inhibiting genes that start the inflammatory process (Scaioli et al., 2018).

Both EPA and DHA are important for the proper functioning of various tissues like blood vessels, heart, eyes and nerves, since, they facilitate the normal growth, development and function of some tissues (Das, 2000).

Omega-3 PUFAs may improve endothelial function by inducing endothelial relaxation and arterial compliance, possibly through improved endothelium mediated vasodilatation induced by altered nitric oxide production (Morgan et al., 2006).

Both omega-3 and omega-6 PUFAs can influence reproductive processes where they provide the precursors for prostaglandin synthesis which is considered as essential components of all cell membranes. The proportions of different PUFAs in tissues of the reproductive tract reflect dietary consumption. Moreover, they may be beneficial for improving sperm motility and viability following acute doxorubicin-induced injury (Uygur et al., 2014). In addition, Hosseini et al. (2019) indicated that supplementing infertile men with omega-3 fatty acids resulted in a significant improvement in sperm motility and concentration of DHA in seminal plasma.

Owing to the anti-oxidant properties of omega-3 PUFAs, it normalized the weight reductions induced in prostate, seminal vesicles and testes and protected against the decrease in sperm count, motility and viability as well as, the increase in sperm abnormalities (Kumar et al., 2011).

In addition, omega-3 PUFAs reduce the lipid peroxidation level and improves the oxidative stress in vitro induced impairment in sperm motility and availability (Bansal and Bilaspuri, 2009).

So, this study was assessed to evaluate the effect of omega-3PUFAs on sperm parameters including; sperm motility, sperm cell concentration and abnormalities. Serum testosterone level, testicular catalase and malondialdehyde concentrations. Body weight and sex organs (testis, prostate gland and seminal vesicles) weights. Histopathological examination of testis.

\section{MATERIALS AND METHODS}

The procedures in this research were approved by the Animal Welfare and Research Ethics Committee, Faculty of Veterinary Medicine, Zagazig University, Egypt.

Animals and diets: In the current study 50 healthy adult male albino rats weighing $200 \pm 20 \mathrm{~g}$ with average age 3-4 months were used. Animals were obtained from Laboratory Animal Unit in Faculty of Veterinary Medicine, Zagazig University. Animals were housed at $23 \pm 1{ }^{\circ} \mathrm{C}$ under a 12 -h light/dark cycle, water and food were available ad-libitum. Rats were fed for 8 weeks on normal diet (18\% protein, $14 \%$ fiber, $2 \%$ fat and $2600 \mathrm{kcal} \mathrm{kg}^{-1}$ ) according to NRC. (1995).

Drugs: Omega-3 PUFAs were obtained from SEDICO pharmaceutical company (6 October city-Egypt), each capsule contain $180 \mathrm{mg}$ of EPA and $120 \mathrm{mg}$ of DHA that is total of $300 \mathrm{mg}$ of omega-3 PUFAs, so, one fish oil capsule or pill is composed of $30 \%$ omega- 3 PUFAs.

Experimental protocol: The animals were divided into 2 equal groups; group A that kept as control $(n=25)$ and group $\mathrm{B}(\mathrm{n}=25)$ where rats subjected to oral administration of omega-3 PUFAs in a dose of $375 \mathrm{mg} \mathrm{kg} \mathrm{kg}^{-1}$ body weight daily for 8 weeks using stomach tube (Kumar et al., 2011). Samples were taken from both treated and control animals at the end of the experiment.

Cauda epididymal spermatozoa collection: The $0.1 \mathrm{~g}$ of the cauda epididymis of the testis was excised, received in a sterilized Petri dish containing $2 \mathrm{~mL}$ warm saline 
$\left(37^{\circ} \mathrm{C}\right)$ then it was macerated by sterilized scissor to obtain the epididymal contents in a suspension that was handled exactly as the semen (Hafez, 1970).

\section{Semen analysis}

Individual motility (\%): Sperm motility was assessed as soon as possible after extraction. A drop of the suspension was put on a clean glass slide and covered by a glass cover slide both pre-warmed at $37^{\circ} \mathrm{C}$. Percentage of forward progressive motile spermatozoa was recorded through examination under high power objective lens (40x) of light microscope according to Sikka et al. (1995).

Sperm cell concentration: The spermatozoa were counted by hem cytometer counting chamber, according to the method described by Robb et al. (1978).

Sperm abnormalities: The percentage of abnormal spermatozoa was determined using eosin-nigrosin stain. according to Bearden and Fuquay (1980).

Organs: The sex organs (testis, seminal vesicle and prostate gland ) were taken from both control and treated animals, weighed, then one testis was fixed in Bouin's solution for further histological examination and other testis was washed in ice-cold saline and used for preparation of tissue homogenates.

Preparation of tissue homogenates: Immediately after removal, one testis from each rat was washed in ice-cold saline and then used to prepare a $10 \%(\mathrm{w} / \mathrm{v})$ homogenate in $0.1 \mathrm{M}$ Tris buffer ( $\mathrm{pH}$ 7.4) with Glas-Col motor driven homogenizer (USA) and used for determination of catalase and Malondialdehyde (MDA) concentrations (Buege and Aust, 1978).

Serum for hormonal assay: Whole blood samples were collected during scarifying the animals into clean tubes without anticoagulant. Blood samples were allowed to clot at room temperature for 20-30 min then centrifuged at $3000 \mathrm{rpm}$ for $15 \mathrm{~min}$. The obtained sera were kept in clean sterile tubes at $-80^{\circ} \mathrm{C}$ until used for determination of testosterone hormone.

Measurement of serum testosterone level: Serum testosterone was carried out using a commercial kit* Testosterone Enzyme Immunoassay (EIA) DSL-10-4000 obtained from Diagnostic Systems Laboratories Inc. according to Burtis and Ashwood (1994).

Determination of catalase concentration: Catalase level was assessed by using a commercial kit* obtained from Diagnostic Systems Laboratories Inc. according to Aebi (1984) and Fossati et al. (1980).
Determination of lipid peroxidation (Malondialdehyde concentration): Malondialdehyde concentration was measured by using a commercial kit obtained from Diagnostic Systems Laboratories Inc. It is based on the colorimetric reaction with Thiobarbituric Acid (TBA) to form pink colored product in acidic medium ( $\mathrm{pH} 2-3)$ and at temperature $90-100^{\circ} \mathrm{C}$ for $15 \mathrm{~min}$. The pink colored product can be measured by spectrophotometer at $532 \mathrm{~nm}$, according to Satoh (1978), Ohkawa et al. (1979), Janero (1990).

Body weight and sex organs (testis, prostate gland and seminal vesicles) weights: were recorded in both control and treated group at the end of the experiment.

Histological examination of testis: Specimens from the testes from both groups were collected and fixed in Bouin's solution, dehydrated in gradual ethanol (70-100\%), cleared in xylene and embedded in paraffin. Five-micron thick paraffin sections were prepared and then routinely stained with Hematoxylin and Eosin (HE) dyes (Bancroft et al., 2013) and then examined microscopically.

Statistical analysis: Data were analyzed using one-way Analysis of Variance (ANOVA) through the General Linear Models (GLM) procedure of the Statistical Package for Social Sciences Version 21.0 (Anonmous, 2012) for Windows 21.0, Inc., Chicago, IL, USA). The comparison of means was carried out with Duncan's Multiple Range Tests (DMRT). Were presented as mean \pm Standard Errors (SE). The value of $\mathrm{p}<0.05$ was used to indicate statistical significance.

\section{RESULTS AND DISCUSSION}

It is obvious from Table 1 that group B (omega-3 PUFAs treated rats ) showed a significant increase in the percentage of motile spermatozoa $(97.00 \pm 0.77 \%)$ as compared with group A $(86.67 \pm 1.67 \%)$, a significant increase in sperm cell concentration $\left(95.17 \pm 1.76 \times 10^{6} \mathrm{~mL}\right)$ as compared with group A $\left(55.00 \pm 2.89 \times 10^{6} \mathrm{~mL}\right)$ and a significant decrease in the percentage of abnormal spermatozoa (17.67 $\pm 0.49 \%)$ as compared with group A $(30.00 \pm 0.58 \%)$.

Concerning, the results from Table 2, group B revealed a significant increase in serum testosterone level $\left(11.60 \pm 0.21 \mathrm{ng} \mathrm{mL}^{-1}\right)$ as compared with group $\mathrm{A}$ $\left(5.33 \pm 0.09 \mathrm{ng} \mathrm{mL}^{-1}\right)$, a significant increase in level of testicular catalase $\left(0.66 \pm 0.00 \mathrm{U} \mathrm{g}^{-1}\right)$ as compared with group A $\left(0.40 \pm 0.00 \mathrm{U} \mathrm{g}^{-1}\right)$ and a significant decrease in level of malondialdehyde $(2.78 \pm 0.09 \mathrm{nmol} /)$ as compared with group A $\left(4.77 \pm 0.35 \mathrm{nmol} \mathrm{g}^{-1}\right)$.

The body weight and sex organs weight (testis, prostate gland and seminal vesicle) showed no change in group B $(350.33 \pm 19.5,1.60 \pm 0.04,0.81 \pm 0.12,1.82 \pm 0.22$, 
Table 1: The overall means of semen parameter of adult male rats supplemented with omega-3 PUFAs

\begin{tabular}{lll}
\hline Parameters & Group A & Group B \\
\hline Sperm motility $(\%)$ & $86.67 \pm 1.67^{\mathrm{b}}$ & $97.00 \pm 0.77^{\mathrm{a}}$ \\
Sperm count $\left(\times 10^{6} \mathrm{~mL}^{-1}\right)$ & $55.00 \pm 2.89^{\mathrm{c}}$ & $95.17 \pm 1.76^{\mathrm{a}}$ \\
Sperm abnormalities (\%) & $30.00 \pm 0.58^{\mathrm{a}}$ & $17.67 \pm 0.49^{\mathrm{c}}$ \\
\hline Means carrying different superscripts within the same column are sig. \\
different at $\mathrm{p}<0.05$ based on Duncan's Multiple Range Test (DMRT)
\end{tabular}

Table 2: The overall means of serum testosterone, testicular catalase and testicular malondialdehyde concentrations of adult male rats supplemented with omega-3 PUFAs

\begin{tabular}{lll}
\hline Parameters & Group A & Group B \\
\hline Serum testosterone $\left(\mathrm{ng} \mathrm{mL}^{-1}\right)$ & $5.33 \pm 0.09^{\mathrm{c}}$ & $11.60 \pm 0.21^{\mathrm{a}}$ \\
Testicular catalase $\left(\mathrm{U} \mathrm{g}^{-1}\right)$ & $0.40 \pm 0.00^{\mathrm{c}}$ & $0.66 \pm 0.00^{\mathrm{a}}$ \\
Testicular malondialdehyde $\left(\mathrm{nmol} \mathrm{mL} \mathrm{mL}^{-1}\right)$ & $4.77 \pm 0.35^{\mathrm{a}}$ & $2.78 \pm 0.09^{\mathrm{b}}$ \\
\hline
\end{tabular}

Means carrying different superscripts within the same column are sig. different at $\mathrm{p}<0.05$ based on Duncan's Multiple Range Test (DMRT)

Table 3: The overall means of body weight and sex organs weight of adult male rats supplemented with omega-3 PUFAs

\begin{tabular}{lll}
\hline Parameters (g) & Group A & Group B \\
\hline Body weight & $432.33 \pm 28.67^{\mathrm{a}}$ & $350.33 \pm 19.54^{\mathrm{a}}$ \\
Testis weight & $1.65 \pm 0.03^{\mathrm{a}}$ & $1.60 \pm 0.04^{\mathrm{a}}$ \\
Prostate gland weight & $0.52 \pm 0.01^{\mathrm{a}}$ & $0.81 \pm 0.12^{\mathrm{a}}$ \\
Seminal vesicle weight & $2.19 \pm 0.19^{\mathrm{a}}$ & $1.82 \pm 0.22^{\mathrm{a}}$ \\
\hline
\end{tabular}

Means carrying different superscripts within the same column are sig. different at $\mathrm{p}<0.05$ based on Duncan's Multiple Range Test (DMRT)

respectively) as compared with group A (432.33 \pm 28.67 , $1.65 \pm 0.03, \quad 0.52 \pm 0.01, \quad 2.19 \pm 0.19$, respectively) as observed in Table 3.

Hisological examination of testis: Omega-3 PUFAs play an important role in the fertility process of both human and animal, especially, EPA and DHA have a significant effect on sperm motility and morphology where many studies revealed a positive correlation of semen quality and food enriched with omega-3 PUFAs as the lipid composition of the sperm membrane plays a role in the functions of spermatozoa where the deficiency of DHA in human spermatozoa produced infertility (Esmaeili et al., 2015).

In addition, it is obvious from Table 1 that the sperm motility and concentration showed a significant increase and the percentage of abnormal spermatozoa showed a significant decrease after omega-3 administration, these results are parallel to the previous findings of Kumar et al. (2011) who revealed that omega-3 PUFAs protected against the decrease in sperm count, motility and viability as well as the increase in sperm abnormalities. Owing to its the anti-oxidant properties (Fig. 1 and 2).

Furthermore, the semen quality might be improved when the concentration of PUFA, in the sperm membranes was increased following supplementation with long-chain omega-3 PUFAs where the total sperm number and sperm motility were improved when boars were supplemented with fish oil (Wathes, 2007).

In the same respect, Estienne et al. (2008) concluded that treatment with omega-3 PUFAs increased the sperm

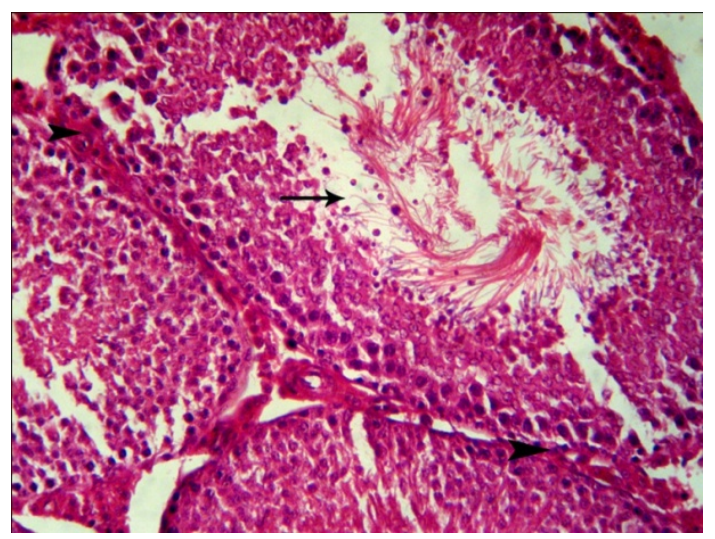

Fig. 1: Testis of control rats (group A) shows few round cells among the spermatozoa in the lumen of the seminiferous tubules (arrow) and normal leydig cells in the interstitium (arrowheads). HE $\times 400$

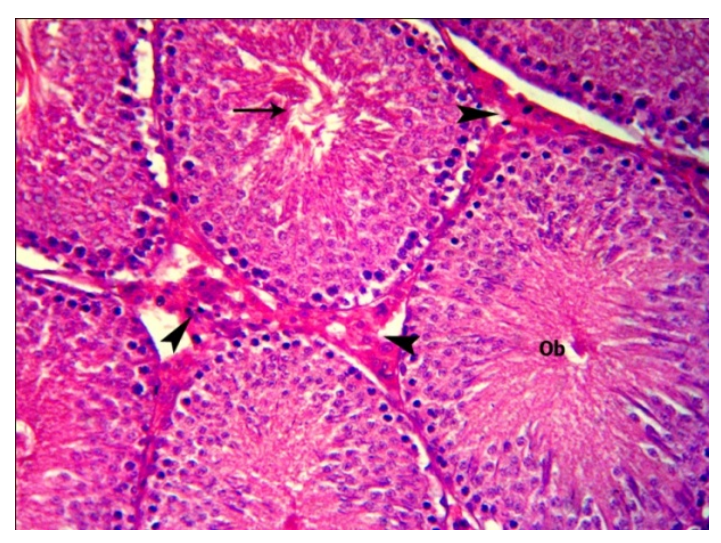

Fig. 2: Testis of omega-3 PUFAs treated rats (group B) shows increase the thickness of the seminiferous tubules by proliferated spermatocytes, narrowing the lumen (ob) (arrow) with huge numbers of spermatozoa (arrow) and increase of the leydig cells in the interstitium (arrowheads). $\mathrm{HE} \times 200$

cell concentration and reduced the percentages of sperm with abnormal tails and bent tails without any effect on sperm morphology.

It had been reported that diet containing high DHA concentrations increased certain spermatozoa characteristics, including percentage of motile cells and cells with normal acrosome scores in stallions (Harris et al., 2005). Furthermore, Brinsko et al. (2005) concluded that feeding a DHA-enriched diet to stallions caused an improvement in motion characteristics of stallions spermatozoa. Also, the high concentration of DHA in both ejaculate and spermatozoa had a positive influence on membrane fluidity that necessary for sperm motility in humans (Lin et al., 2004). 
Similarly, Elelaimy et al. (2012) revealed that treatment with omega-3 PUFAs completely reduced the percentage of sperm abnormalities induced by azathioprine. On other hand Marc et al. showed that supplementing boar's diet with omega-3 PUFA did not affected sperm concentration, sperm viability and sperm motility when compared with control diet.

Regarding, serum testosterone level, Table 2 showed a significant increase in testosterone level in omega-3 treated groups. These result confirmed the previous results of Kumar et al. (2011) who found that the levels oftestosterone increased gradually with omega-3 fatty acids treatment. In addition, Ismail et al. (2011) reported that $\omega-3$ fatty acids in rats produced an increase in blood testosterone levels. Similarly, in men, it was found that intake of DHA influenced serum testosterone concentration (Nagata et al. 2000) and rats fed omega-3 PUFAS showed an elevation in testosterone concentration (De Catalfo et al., 2008).

Sperm cell plasma membrane is differ from most of other cell membranes in lipid composition where it contains high amount of Poly Unsaturated Fatty Acids (PUFA), this structure of the sperm resulting in greater sensitivity to the environmental hazards compared with other cells (Osman et al., 2015).

Gual-Frau et al. (2015) reported that the harmful effect of ROS is due to its ability to reduce axonemal protein phosphorylation which associated with a decrease in membrane fluidity through propagating PUFA hydro peroxidation, in addition, it can diffuse into the cells and inhibit the activity of Glucose-6-Phosphate Dehydrogenase (G6PD) which considered as a key enzyme in controlling the intracellular viability of NADPH-dependent antioxidant enzymes.

Lipid per-oxidation lead to damage of the lipid matrix in the sperm cell membrane which resulted in germ cell death at the different stages of development loss of motility and impairment of spermatogenesis, so, antioxidant therapy act as a protective defense against oxidative stress and so, improve the fertility parameters (Bestas et al., 2006).

It is obvious from the data in Table 2 that the antioxidant enzyme (catalase) level showed significant increase after oral administration of omega- 3 as compared to control group. This agree with Rezk et al. (2011) who revealed that oral administration of omega-3 caused a significant increase in the activity of antioxidant enzymes GPX, SOD and CAT. In addition, Safarinejad et al. (2010) reported that catalase level was significantly low in infertile patients and correlated with sperm concentration, sperm motility and sperm morphology. In addition, there were significant positive correlations between spermatozoa omega-3 PUFAS and catalase-like activity. Also, pretreatment with omega-3 PUFAs and selenium produced an-ant oxidative effect by decreasing lipid peroxidation and maintaining normal levels of catalase activities (Attia and Nasr, 2009). In addition, Martinez-Soto et al. (2016) concluded that dietary DHA supplementation induced an increase of omega-3 PUFAs and DHA concentration in seminal plasma, produced an increase in total antioxidant capacity and a lower sperm DNA fragmentation.

On the other hand Tabei et al. (2015) revealed that catalase activity was significantly decreased in the heart and liver of diabetic rats and supplementation with omega-3PUFAS induced no change in catalase activity.

Concerning, malondialdehyde level, these results observed in Table 2 are in agreement with the previous findings of Ismail et al. (2011); Meydan et al. (2012) who demonstrated that omega-3 PUFAs decreased malondialdehyde. Furthermore, Ozyurt et al. (2008) demonstrated that omega-3PUFAs treatment significantly decreased oxidative injury. In the same respect Rezk et al. (2011) revealed that oral administration of omega-3 PUFAs supplement induced a significant decrease in MDA content in testis and cerebral cortex tissues in rats.

The present study revealed no changes in body weight and sex organ (testis, prostate gland and seminal vesicles) weights of adult male rats treated with omega-3 PUFAs (Table 3). Similarly, Castellano et al. (2011) found that the body and reproductive organ weights were not significantly affected by dietary treatments of omega-3PUFAs. Also, Suh et al. (2011) found that omega- 3 treatment did not affect the sex organ weights. On the other hand Zidkova et al. (2004) revealed that high content of cod liver oil in diet caused a significant reduction in the weight of testicles, epididymis and seminal vesicles.

The histological picture of testes showed numerous sperms in lumen of the seminiferous tubules with numerous active spermatocytes in omega-3 PUFAs treatment, this could be attributed to the effect of increased testosterone level where androgens possess anabolic activities, important for the development, growth and normal function of the testis and production of normal spermatozoa (Johnson and Everitt, 1988). In addition, omega-3 PUFAs were expected to protect testicular tissue due to their antioxidant properties (Kumar et al., 2011). In addition, Ismail et al. (2011) reported that omega-3 fatty acid had favorable effects in rat testis tissue by preventing damage and increasing the level of testosterone.

\section{CONCLUSION}

Our results suggested that omega-3 PUFAs had a positive and beneficial effects on the male fertility as represented by an increase in the sperm motility, sperm cell concentration with a reduction of the sperm 
abnormalities. These improvements may be attributed to the increase in testosterone level which stimulates spermatogenesis, testicular function and heightened the male copulatory behavior. In addition, the results showed a significant increase in catalase activity indicating anti-oxidant properties of omega-3 and significant decrease in MDA levels, suggesting its effect on decreasing lipid peroxidation. So, it could be recommended the use of omega-3 PUFAS for improving the semen quality, fertility and reproductive performance of males. improve the fertility, sexual function of the male and semen quality.

\section{REFERENCES}

Aebi, H., 1984. Catalase in vitro. Meth. Enzymol., 105: 121-126.

Anonymous, 2012. SPSS Statistical Package for Windows, Version 21.0. SPSS Inc., Chicago, IL., USA.

Attia, A.M. and H.M. Nasr, 2009. Evaluation of the protective effect of omega-3 fatty acids and Selenium on paraquat intoxicated rats. Slovak J. Anim. Sci., 42: 180-187.

Austin, D.F., 1991. Ipomoea littoralis (Convolvulaceae)-taxonomy, distribution and ethnobotany. Econ. Bot., 45: 251-256.

Bancroft, J.D., C. Layton and S.K. Suvarna, 2013. Bancroft's Theory And Practice Of Histological Techniques. 7th Edn., Churchill Livingstone, Edinburgh, Scotland, ISBN-13: 9780702050329, Pages: 151.

Bansal, A.K. and G.S. Bilaspuri, 2009. Impacts of oxidative stress and antioxidants on semen functions. Anim. Sci. Pap. Rep., 27: 5-14.

Bearden, H.J. and J.W. Fuquay, 1980. Applied Animal Reproduction. Reston Publishing Co., Inc., Reston, Virginia, pp: 157-165.

Bestas, A., M.K. Bayar, N. Akpolat and M.N. Okuducu, 2006. Effect of sevoflurane anesthesia on the severity of renal histopathologic changes in rabbits pretreated with gentamicin: A controlled, investigator-blinded, experimental study. Curr. Ther. Res., 67: 386-395.

Brinsko, S.P., D.D. Varner, C.C. Love, T.L. Blanchard, B.C. Day and M.E. Wilson, 2005. Effect of feeding a DHA-enriched nutriceutical on the quality of fresh, cooled and frozen stallion semen. Theriogenology, 63: 1519-1527.

Buege, J.A. and S.D. Aust, 1978. Microsomal lipid peroxidation. Methods Enzymol., 52: 302-310.

Burtis, C.A. and E.R. Ashwood, 1994. Tietz Textbook of Clinical Chemistry. 2nd Edn., W.B. Saunders, Philadelphia, pp: 1002-1093.
Castellano, C.A., I. Audet, J.P. Laforest, J.J. Matte and M. Suh, 2011. Fish oil diets alter the phospholipid balance, fatty acid composition and steroid hormone concentrations in testes of adult pigs. Theriogenology, 76: 1134-1145.

Das, U.N., 2000. Beneficial effect(s) of n-3 fatty acids in cardiovascular diseases: But, why and how?. Prost. Leuk. Essent. Fatty Acids (PLEFA), 63: 351-362.

De Catalfo, G.E.H., M.J. de Alaniz and C.A. Marra, 2008. Dietary lipids modify redox homeostasis and steroidogenic status in rat testis. Nutrition, 24: 717-726.

Elelaimy, I.A., S.A. Elfiky, A.M. Hassan, H.M. Ibrahim and R.I. Elsayad, 2012. Genotoxicity of anticancer drug azathioprine (Imuran): Role of omega-3 ( $\omega-3)$ oil as protective agent. J. Applied Pharm. Sci., 2: 14-23.

Esmaeili, V., A.H. Shahverdi, M.H. Moghadasian and A.R. Alizadeh, 2015. Dietary fatty acids affect semen quality: A review. Andrology, 3: 450-461.

Estienne, M.J., A.F. Harper and R.J. Grawford, 2008. Dietary supplementation with a source of omega-3 fatty acids increases sperm number and the duration of ejaculation in boars. Theriogenology, 70: 70-76.

Fossati, P., L. Prencipe and G. Berti, 1980. Use of 3,5-dichloro-2-hydroxybenzenesulfonic acid/4-aminophenazone chromogenic system in direct enzymic assay of uric acid in serum and urine. Clin. Chem., 26: 227-231.

Giahi, L., S. Mohammadmoradi, A. Javidan and M.R. Sadeghi, 2015. Nutritional modifications in male infertility: A systematic review covering 2 decades. Nutr. Rev., 74: 118-130.

Gual-Frau, J., C. Abad, M.J. Amengual, N. Hannaoui and M.A. Checa et al., 2015. Oral antioxidant treatment partly improves integrity of human sperm DNA in infertile grade I varicocele patients. Hum. Fertil., 18: 225-229.

Hafez, E.S.E., 1970. Reproduction and Breeding Techniques for Laboratory Animals. Lea and Febiger, Philadelphia, pp: 299-315.

Harris, M.A., L.H. Baumgard, M.J. Arns and S.K. Webel, 2005. Stallion spermatozoa membrane phospholipid dynamics following dietary n-3 supplementation. Anim. Reprod. Sci., 89: 234-237.

Hosseini, B., M. Nourmohamadi, S. Hajipour, M. Taghizadeh, Z. Asemi, S.A. Keshavarz and S. Jafarnejad, 2019. The effect of omega-3 fatty acids, EPA and/or DHA on male infertility: A systematic review and meta-analysis. J. Dietary Suppl., 16: 245-256.

Ismail, Z., K. Ilter, D. Mursel, K.A. Murat, K. Dilara and S. Mustafa, 2011. The protective effects of omega-3 fatty acids on rat testicular tissue. Dicle Med. J., 38: 382-386. 
Janero, D.R., 1990. Malondialdehyde and thiobarbituric acid-reactivity as diagnostic indices of lipid peroxidation and peroxidative tissue injury. Free Radical Biol. Med., 9: 515-540.

Johnson, M. and B. Everitt, 1980. Essential Reproduction. 6th Edn., Blackwell Scientific Publ., Oxford, England, ISBN: 9781405118668, pp: 64-93.

Kumar, A.S., K.B. Deepthi, M.D.V. Prasad, P.G. Mary, S.S. Kumar and M. Swathi, 2011. Evaluation of the protective effects of omega-3 fatty acids against methotrexate induced testicular toxicity in male albino mice. Int. J. Phytopharmacol., 2: 48-52.

Lin, D.S., M. Neuringer and W.E. Connor, 2004. Selective changes of docosahexaenoic acid-containing phospholipid molecular species in monkey testis during puberty. J. Lipid Res., 45: 529-535.

Martinez-Soto, J.C., J.C. Domingo, B. Cordobilla, M. Nicolas and L. Fernandez et al., 2016. Dietary supplementation with Docosa Hexaenoic Acid (DHA) improves seminal antioxidant status and decreases sperm DNA fragmentation. Syst. Biol. Reprod. Med., 62: 387-395.

Meydan, S., M. Altas, A. Nacar, O.H. Ozturk, U. Tas, I. Zararsiz and M. Sarsilmaz, 2012. The protective effects of omega-3 fatty acid against toluene-induced neurotoxicity in prefrontal cortex of rats. Hum. Experimental Toxicology, 31: 1179-1185.

Morgan, D.R., L.J. Dixon, C.G. Hanratty, N. El-Sherbeeny and P.B. Hamilton et al., 2006. Effects of dietary omega-3 fatty acid supplementation on endothelium-dependent vasodilation in patients with chronic heart failure. Am. J. Cardiol., 97: 547-551.

NRC., 1995. Nutrient Requirements of Laboratory Animals. 4th Edn., National Academic Press, Washington DC., USA., ISBN: 0-309-05126-6.

Nagata, C., N. Takatsuka, N. Kawakami and H. Shimizu, 2000. Relationships between types of fat consumed and serumestrogen and androgen concentrations in Japanese men. Nutr. Cancer, 38: 163-167.

Ohkawa, H., N. Ohishi and K. Yagi, 1979. Assay for lipid peroxides in animal tissues by thiobarbituric acid reaction. Anal. Biochem., 95: 351-358.

Osman, A., H. Alsomait, S. Seshadri, T. El-Toukhy and Y. Khalaf, 2015. The effect of sperm DNA fragmentation on live birth rate after IVF or ICSI: A systematic review and meta-analysis. Reprod. Biomed. Online, 30: 120-127.

Ozyurt, B., F. Erdemir, B.S. Parlaktas, H. Ozyurt, H. Erdogan and A.T. Tunc, 2008. Effects of Omega-3 on lipid peroxidation and antioxidant enzymes in MK-801 induced schizophrenic rat testis. Turk. J. Med. Sci., 38: 301-306.
Rezk, R.G., Z. Abou and A.G. Ahmed, 2011. Role of omega 3 fatty acids on radiation-induced oxidative and structural damage in different tissues of male albino rats. J. Radiat. Res. Applied Sci., 4: 761-776.

Rizos, E.C., E.E. Ntzani, E. Bika, M.S. Kostapanos and M.S. Elisaf, 2012. Association between omega-3 fatty acid supplementation and risk of major cardiovascular disease events: A systematic review and meta-analysis. JAMA., 308: 1024-1033.

Robb, G.W., R.P. Amann and G.J. Killian, 1978. Daily sperm production and epididymal sperm reserves of pubertal and adult rats. J. Reprod. Fertil., 54: 103-107.

Safarinejad, M.R., S.Y. Hosseini, F. Dadkhah and M.A. Asgari, 2010. Relationship of omega-3 and omega-6 fatty acids with semen characteristics, and anti-oxidant status of seminal plasma: A comparison between fertile and infertile men. Clin. Nutr., 29: 100-105.

Saleh, R.A. and A. Agarwal, 2002. Oxidative stress and male infertility: From research bench to clinical practice. J Androl., 23: 737-752.

Satoh, K., 1978. Serum lipid peroxide in cerebrovascular disorders determined by a new colorimetric method. Clin. Chim. Acta, 90: 37-43.

Scaioli, E., A. Sartini, M. Bellanova, M. Campieri, D. Festi, F. Bazzoli and A. Belluzzi, 2018. Eicosapentaenoic acid reduces fecal levels of calprotectin and prevents relapse in patients with ulcerative colitis. Clin. Gastroenterol. Hepatol., 16: 1268-1275.

Scorletti, E. and C.D. Byrne, 2013. Omega-3 fatty acids, hepatic lipid metabolism and nonalcoholic fatty liver disease. Annu. Rev. Nutr., 33: 231-248.

Seo, T., W.S. Blaner and R.J. Deckelbaum, 2005. Omega-3 fatty acids: Molecular approaches to optimal biological outcomes. Curr. Opin. Lipidol., 16: 11-18.

Sikka, S.C., M. Rajasekaran and W.J. Hellstrom, 1995. Role of oxidative stress and antioxidants in male infertility. J. Androl., 16: 464-481.

Suh, M., K.J. Merrells, A. Dick and C.G. Taylor, 2011. Testes of obese rats are highly responsive to $n-3$ long-chain fatty acids. Br. J. Nutr., 106: 1005-1012.

Tabei, S.M., S. Fakher, M. Djalali, M.H. Javanbakht and M. Zarei et al., 2015. Effect of vitamins A, E, C and omega-3 fatty acids supplementation on the level of catalase and superoxide dismutase activities in streptozotocin-induced diabetic rats. Bratislavske Lekarske Listy, 116: 115-118.

Toshimori, K., C. Ito, M. Maekawa, Y. Toyama, F. Suzuki-Toyota and D.K. Saxena, 2004. Impairment of spermatogenesis leading to infertility. Anat. Sci. Int., 79: 101-111. 
Uygur, R., C. Aktas, F. Tulubas, E. Uygur and M. Kanter et al., 2014. Protective effects of fish omega-3 fatty acids on doxorubicin-induced testicular apoptosis and oxidative damage in rats. Andrologia, 46: 917-926.

Wathes, D.C., D.R. Abayasekara and R.J. Aitken, 2007. Polyunsaturated fatty acids in male and female reproduction. Biol. Reprod., 77: 190-201.
Yeste, M., X. Barrera, D. Coll and S. Bonet, 2011. The effects on boar sperm quality of dietary supplementation with omega-3 polyunsaturated fatty acids differ among porcine breeds. Theriogenology, 76: 184-196.

Zidkova, J., J. Sajdok, K. Kontrova, A. Kotrbova-Kozak, T. Hanis, V. Zidek and A. Fucikova, 2004. Effects of oxidised dietary cod liver oil on the reproductive functions of Wistar rat. Czech J. Food Sci., 22: $108-120$. 